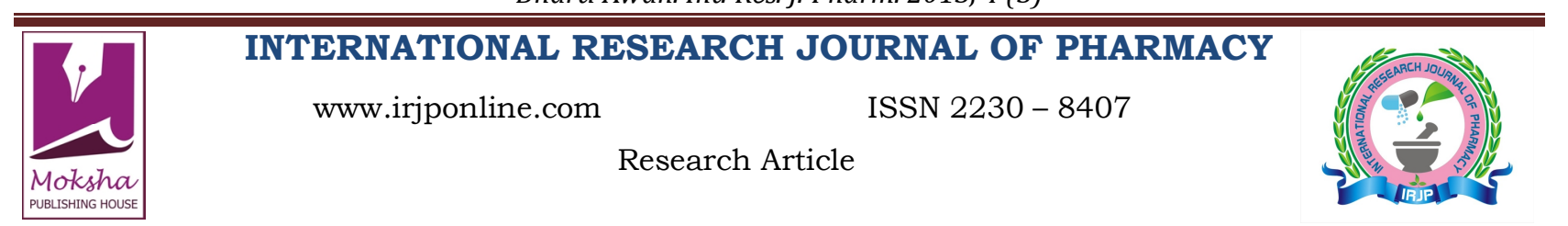

\title{
DETERMINATION OF QUERCETIN IN EXTRACT OF ELAEOCARPUS GANITRUS ROXB. SEEDS BY USING HPTLC METHOD
}

\author{
Bharti Awan* \\ Department of Pharmacognosy, Shri Rawatpura Sarkar Institute of Pharmacy, Datia, M.P., India \\ Email: bhartiawan@gmail.com
}

Article Received on: 19/01/13 Revised on: 01/02/13 Approved for publication: 11/03/13

DOI: $10.7897 / 2230-8407.04339$

IRJP is an official publication of Moksha Publishing House. Website: www.mokshaph.com

(C) All rights reserved.

\begin{abstract}
Herbal medicines have good efficacy, safety, and lesser side effects. They have great demand in developed world for primary health care. India has rich traditional knowledge, heritage of herbal medicines and large biodiversity but despite it India has dismal share of world market. Many Pharma companies marketed herbal preparation as neutraceutical and took excuses from quality control parameter set by W.H.O. India has thousands of medicinal plants but in Indian Pharmacopoeia. Quercetin, one of the most abundant natural flavonoids, presents in daily food. Quercetin is of interest because of its pharmacological function. The quantitative determination of flavonoids compound in seeds of Elaeocarpus ganitrus was carried out in high performance thin layer chromatography. Concentration of quercetin in Elaeocarpus ganitrus seeds was calculated based on calibration curve.
\end{abstract}

Keywords: Elaeocarpus ganitrus Seeds, HPTLC, Quercetin

\section{INTRODUCTION}

Plants of the genus Elaeocarpus have been reported to be of use as traditional medicines, particularly in India. Elaeocarpus ganitrus (syn: Elaeocarpus sphaericus; Elaeocarpaceae) is a tree found in the Himalayan region of India. The fruits of this plant are commonly known as Rudraksha and have been used in Ayurvedic traditional medicine for the treatment of mental diseases, epilepsy, asthma, hypertension, arthritis and liver diseases ${ }^{1,2,3}$.

Flavonoids occur, either as free molecules or as glycosides. They have widespread occurrence in plant kingdom. They occur ubiquitously in ferns and fern allies (Pteridophyta), conifers (Gymnosperms), dicot and monocots. Chemically, flavonoids show a fifteen-carbon skeleton, which consist of two phenyl rings connected by three carbon bridges. Flavonoids have been found possess a number of biological activities ${ }^{4}$. Flavonoids (flavus- yellow) or bioflavonoid, are a ubiquitous group of poly phenolic substances which are present in most plants, concentrated in the seeds, fruit skin, peel, bark and flowers ${ }^{5}$. They have been used extensively as a chemotaxonomic markers and are abundant in the polygonaceae, rutaceae, leguminosae, umbelliferae and composite. Many flavonoid-containing plants are diuretic or antispasmodic. Some flavonoids have antitumor, antibacterial or antifungal properties ${ }^{6}$. HPTLC is now-a-days applied to obtain "Finger-print" patterns of herbal formulations, quantification of active ingredients and also detection of adulteration. HPTLC is rapidly gaining importance in biochemistry of natural products and in analysis of biofluids in the field of pharmacokinetics ${ }^{4}$. Densitometric HPTLC has been widely used for the phytochemical evaluation of the herbal drugs, due to its simplicity and minimum sample clean up requirement. Hence a densitometric HPTLC method has been developed in the present work for quantitation of quercetin from hydro alcoholic extract of dried flowers of $N$. stellata ${ }^{7}$.

\section{MATERIALS AND METHODS \\ Plant material}

The Methanolic extract of seeds of Elaeocarpus ganitrus were obtained by Soxhlet method. The leaves and seeds of Rudraksha were collected from Bahrich in 2011 from Uttar Pradesh, India. The plant was identified and authenticated by Dr. Tariq Husain, National Botanical Research Institute, Lucknow. The voucher specimen (98159) has been deposited in herbarium.

\section{Standards and reagents}

Chloroform, methanol are used as solvent system, plant sample (1) and anisaldehyde sulfuric acid, ferulic acid (F) and quercetin (2) are used as spraying reagent. The calibration curves were constructed and shown in results.

\section{Preparation of crude extracts}

Accurately weighed 2.0 gm of the coarse powder of Plant sample extracted with methanol and sonicate for 30 minutes. The combined extracts were filtered and prepare $10 \mathrm{mg} / \mathrm{ml}$ solution with analytical grade methanol.

\section{High Performance Thin Layer Chromatography}

HPTLC was performed on $20 \mathrm{~cm} \times 10 \mathrm{~cm}$ TLC glass plates precoated with $200-\mu \mathrm{m}$ layer thickness of silica gel $60 \mathrm{~F}_{254}$ (a d fine-chem. Limited, Mumbai, India). Samples were applied as $6 \mathrm{~mm}$ band width using Camag 100 microlitre sample syringe (Hamilton, Switzerland) with a Linomat 5 applicator (camag, Switzerland) under a flow of $\mathrm{N}_{2}$ gas. The linear ascending development was carried out with Toluene: Ethyl Acetate, $[80: 20 \mathrm{v} / \mathrm{v}]$ for plant samples as mobile phase in a Camag glass twin through chamber $(20 \times 10 \mathrm{~cm})$. The chamber was previously saturated with mobile phase vapour for 8 minutes at room temperature $\left(25 \pm 2{ }^{\circ} \mathrm{C}\right), 50 \% \pm 2$ relative humidity and plates were developed at distances of approximately $80 \mathrm{~mm}$ from the point of application. After development, plates were dried through air dried and scanning were performed using Camag TLC Scanner 3 at $\lambda$ $\max 600 \mathrm{~nm}$ in UV absorbance mode for plant samples operated by win CATS Software [ version 3.2.1]. The shift 
dimensions were $4 \mathrm{~mm} \times 0.45 \mathrm{~mm}$ and the scanning speed was $100 \mathrm{~mm} / \mathrm{s}$.

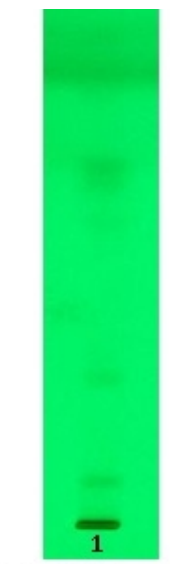

Under UV $254 \mathrm{~mm}$

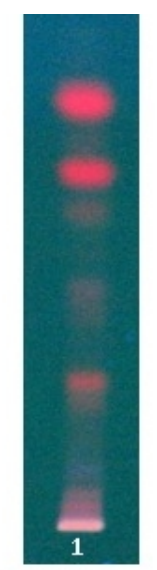

Under UV $366 \mathrm{~nm}$

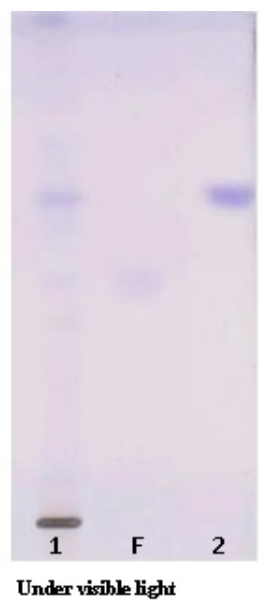

Under visible hight

Figure: 1 Photograph of Chromatogram Obtained at, $254 \mathrm{~nm} 366 \mathrm{~nm}$ and under visible light of extract of Elaeocarpus ganitrus Roxb. Seeds Slides shown that $-1=$ Plant sample, $F=$ Ferulic acid, $2=$ Quercetin

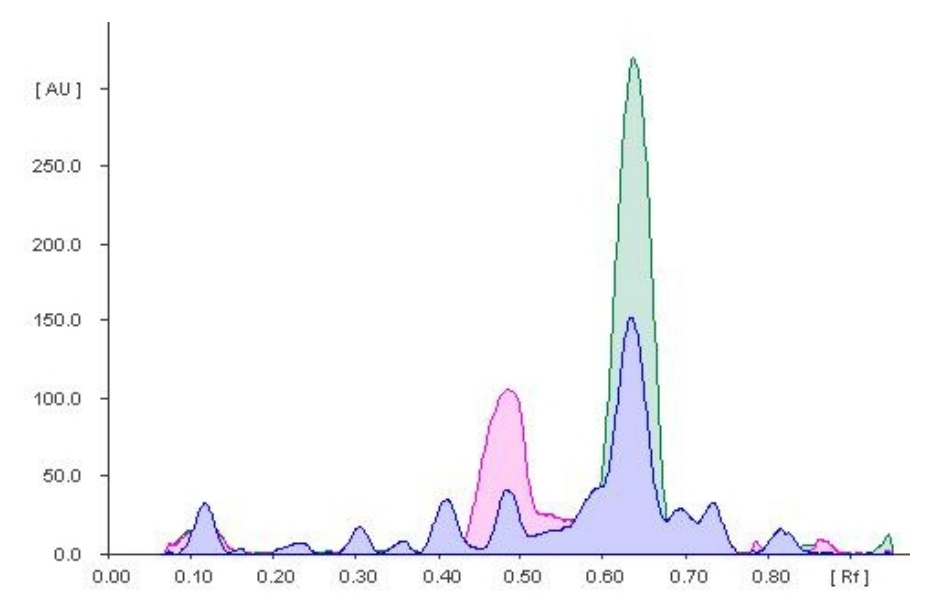

Figure: 2 Densitometric scan profile at $366 \mathrm{~nm}$

Solvent system: Chloroform: Methanol: 95:05

Spraying reagent: Anisaldehyde Sulfuric acid

Ferulic acid in $20 \mu 1$ of sample $=415.96 \mathrm{ng}$

Quercetin in $20 \mu \mathrm{l}$ of sample $=355.39 \mathrm{ng}$

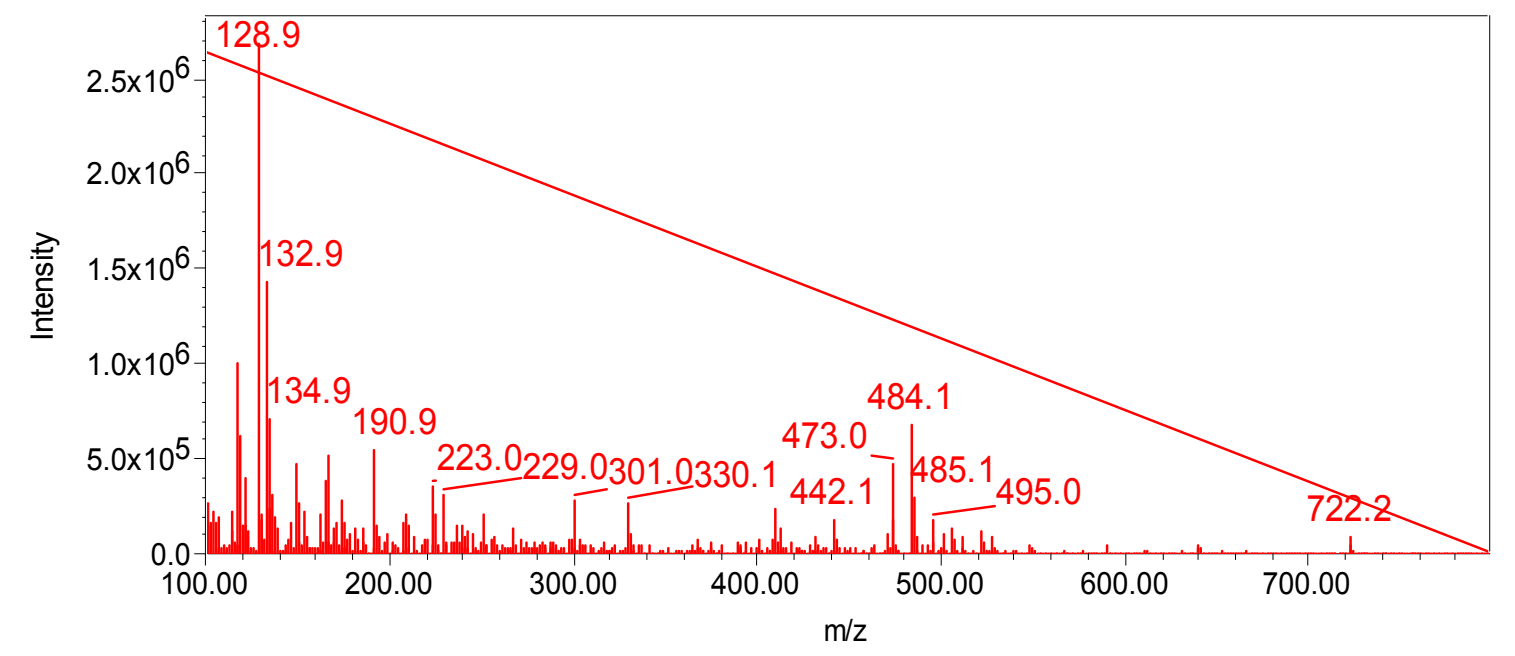

Figure: 3 ESI -MS spectrometry of Quercetin 


\section{RESULT AND DISCUSSION}

The developed HPTLC procedure was precise, specific and accurate $^{8}$. In the final stage of investigation we evaluated the content of flavonoids in seeds of Elaeocarpus ganitrus using parallel Christ-Müller's and after acid hydrolysis HPTLC methods. The content (in mg) of flavonoids according to the Christ-Müller's methods was calculated as quercetin-flavonol type compound and monoside-hyperoside. Results given as hyperoside varied from $3.1 \mathrm{mg} / \mathrm{g}$ to $5.0 \mathrm{mg} / \mathrm{g}$ in seeds. Addition of the latter two standards was necessary as isomerisation of 8-C-glycosides to their 6-C-glycosides derivatives took places during acid hydrolysis. Measurements were made by wavelength $342 \mathrm{~nm}$. Standard curves were prepared for individual standards taking into consideration a relationship between peak area field and standard concentration. The obtained results for flavonoids standards indicate good precision of the method used. Kaempferol and quercetin were found to dominate in seeds of Elaeocarpus ganitrus. The content of C-glycosides derivatives of apigenin and quercetin in all seed samples was in a standard quantity than flavonol type compounds. On the contrary, in sample Cglycosides derivatives of apigenin and luteolin were dominant. The values obtained for flavonoids sum by ChristMüller's method were higher than using HPTLC method after acid hydrolysis, which results from a possible reaction between $\mathrm{AlCl}_{3}$ and non-flavonoid compounds present in the investigated samples.
The final result was shown in figure 1 and 2 . The graph was also shown.

\section{REFERENCES}

1. Singh RK, Acharya SB, Bhattacharya SK. Pharmacological Activity of Elaeocarpus sphaericus. Phytother. Res.; 2000; 14: 36-39. http:// dx.doi.org/10.1002/(SICI)1099-1573(200002)14:1<36::AIDPTR541>3.0.CO;2-J

2. Singh RK, Gopal Nath. Antimicrobial Activity of Elaeocarpus sphaericus. Phytother. Res.; 1999; 13: 448-450. http://dx.doi.org/ 10.1002/(SICI)1099-1573(199908/09)13:5<448::AIDPTR480>3.0.CO;2-6

3. Dasgupta A, Agrawal SS, Basu DK. Anticonvulsant activity of the mixed fatty acids of Elaeocarpus ganitrus Roxb. (Rudraksha). Indian J. Physiol. Pharmacol.; 1984; 28:245-246.

4. Kokate CK, Purohit AP, Gokhle SB, Pharmacognosy. $36^{\text {th }}$ Edition: Nirali Prakashan; 2006. p.231.

5. Rajalakshmi PV, Senthil Kalaiselvi K. Direct HPLC Analysis of Quercetin in exudates of Abutilon indicum (Linn.) Malavaceae. Journal of Pharmaceutical Science and Technology; 2009; Vol. 1 (2):80.

6. Evans WC, Trease and Evans Pharmacognosy: WB Saunders Edinburgh; 2002. p.247.

7. Sachin U. Rakesh et al. HPTLC method for quantitative determination of Quercetin in hydroalcoholic extract of dried flower of Nymphaea stellata Willd. International Journal of ChemTech Research; 2009; Vol.1 (4): 931.

8. Patel DB, Patel NJ. Validated stability indicating HPTLC method for the determination of Tamsulosin hydrochloride in pharmaceutical dosage forms.International Journal of ChemTech Research; 2010; Vol.2 (1):646-652.

Cite this article as:

Bharti Awan. Determination of Quercetin in extract of Elaeocarpus ganitrus Roxb. seeds by using HPTLC method. Int. Res. J. Pharm. 2013; 4(3):186188 